\title{
Editorial
}

\section{Poverty into Wealth}

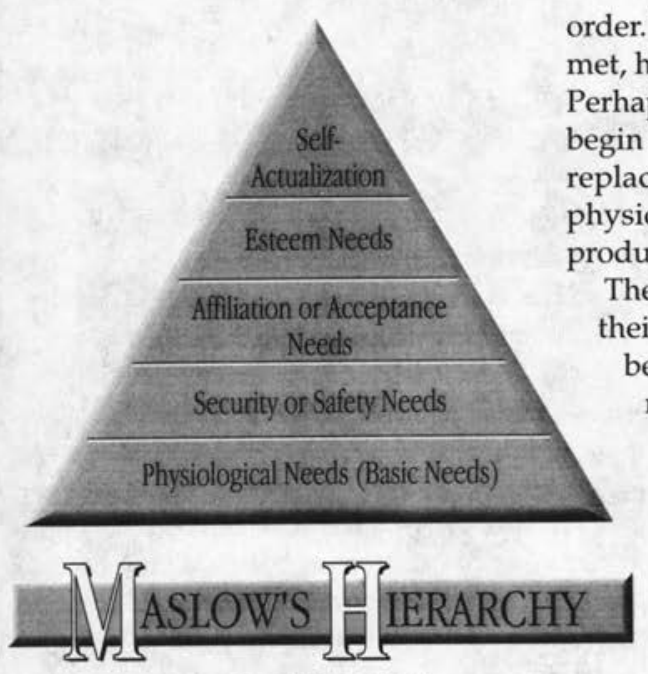

OF NEEDS

On September 1, 1995, Graham B. Spanier became the 16th President of The Pennsylvania State University, the current home of CERL. I began this editorship under his academic leadership as Provost at Oregon State University where Director of Libraries Mel George's recurring lament was that the social contract between the public and its libraries was undergoing a radical change for the worse. Once there had been an agreement that libraries and education were public goods and should be supported without question, but now, increasingly, the public cares more for concrete solutions to easily understood problems. Librarians can perhaps understand this eroding support in terms of Abraham Maslow's hierarchy of needs, a model devised to explain the nature of human motivations, specifically in the professional world. Maslow believed that people are motivated by unmet needs in a hierarchical order. Unless all lower-level needs have been met, higher level ones cannot be addressed. ${ }^{1}$ Perhaps now, educators and librarians must begin to convince the public that education replaces the poverty of simply fulfilling a physical need with the wealth of a happy, productive, and socially beneficial life.

The areas of the hierarchy above represent their relative strength to influence human behavior and the order in which they must be satisfied. This year spending for prisons in California exceeded spending for education. Because prisons represent a concern for safety, near the larger bottom of the hierarchy, and because education represents self-esteem and self-actualization, the electorate funds prisons while college programs close. Education aids individuals in achieving self-actualization which allows them to appreciate concepts, such as the public good. Education must compensate for its loss of the public good mystique and its lesser motivational power by preparing and presenting a stronger case to the public. However, many view education as a means for preventing crime, and, therefore, prisons. Thus, continuing to fund prisons at the expense of education exacerbates the societal problem.

Raymond Smock recognizes the relative strength of appeal inherent in Maslow's hierarchy when he pleads for the National Digital Library Federation (NDLF) to include humanities materials in its selections for digitization. He admits, though, that "we cannot demonstrate that humanities research is directly profitable to the stockholders of the NII (National Information Infrastructure)."2 Preparing materials to be placed in this resource is expensive, costing as much as 
$\$ 100$ a volume for scanning, and requiring frequent, perhaps even annual, refreshing to keep text files readable by current computers. Because the NII is being built and controlled by the private sector, Smock worries about digitized reruns of I Love Lucy pushing out access to Thomas Jefferson's papers. Since the most popular and obvious materials will be made available by the commercial sector, and since both science societies and science publishers are rushing ahead into the digitized world, perhaps the NDLF should pay particular interest to the humanities.

Richard Lucier, a creator of the Genome database and Project Red Sage, recently illustrated the difficulty of competing for funds even inside his own institution, the University of California at San Francisco Health Sciences Center. In 1991 the campus provided 90 percent of the funding for his programs; now it provides only 75 percent. By 1999 he thinks he will be required to generate half the income to support library services on the campus. Sources of income will include such old standbys as photocopying and charging for different types of searches, and such new programs as vending databases and specialized information management aids. ${ }^{3}$ While the timing of this pay-yourown-way scenario may be sooner for Lucier's operation than for more traditional college and university libraries, the direction seems consistent with the observations above.

My colleague Ron Dow and I enjoy a continuing debate on the core nature of an academic library. Dow argues that libraries exist to serve their communities. Collections should be developed and services should be created to satisfy that community's needs. To the extent that the library can discern and meet the primary needs of its community, it prospers. In a business sense, the library must regularly account for its costs to the institution by justifying its existence to the community it serves. Dow maintains that the library as a philosophical construct, whose intrinsic worth on campus is mandated by its very existence, is impractical and out of step with the operating environment of higher education at the end of the 20th century.

I part company with those who:

- demand more money for prisons than education;

- view information only in economic terms;

- insist that the library pay its own way; and

- fail to assign a value to the intrinsic worth of the library on campus.

I maintain that there is an intrinsic worth to a library. The library on campus in not just an organization designed to dole out academic services on a costrecovery basis, whether that cost recovery occurs at the user or institutional level. The library stands for something bigger, for meeting, on the Maslow hierarchy of needs, the human need for learning and culture.

The university has a much broader and nobler mission than selling credit hours. In his "Inaugural State-of-the-University Address," Graham Spanier, speaking about his family's immigration to the United States, concludes, "For me, education is society's mechanism for turning despair into hope, for raising the social consciousness of the community, for altering the course of families, for turning poverty into wealth, and for improving the quality of life. Only education could allow a poor immigrant who grew up on the south side of Chicago to become the President of Penn State." 4 Spanier summarizes here what academics around the country believe about the importance of their contribution to society. We would like to return to those happier days when librarians and education were supported as public goods. Meanwhile, we must invent ways to make our vision of the benefits of higher education as powerful to the public as the vision of incarcerated 
criminals. Society must believe, as educators do, that education turns poverty into wealth.

GLORIANA ST. CLAIR
The editor wishes to thank Ron Dow for this and other ongoing discussions and for his help with the editorial, and Karen Gerboth for her assistance with research and manuscript preparation.

\section{Notes}

1. Ronald L. Pardee, "Motivation Theories of Maslow, Herzberg, McGregor \& McClelland: A Literature Review of Selected Theories Dealing with Job Satisfaction and Motivation," ERIC Document ED316767 (Feb. 1990): 3.

2. Raymond Smock, "What Promise Does the Internet Hold for Scholars?" Chronicle of Higher Education 22 (Sept. 1995): section B2.

3. Richard Lucier, "Knowledge Management: The Co-Existence of Multiple Models of Scientific Communication" (paper presented at conference on Challenging Marketplace Solutions to Problems in the Economics of Information, Washington, D.C., Sept. 18, 1995). 9-12.

4. Graham B. Spanier, "Inaugural State-of-the-University Address," Intercom 21 (Sept. 1995):

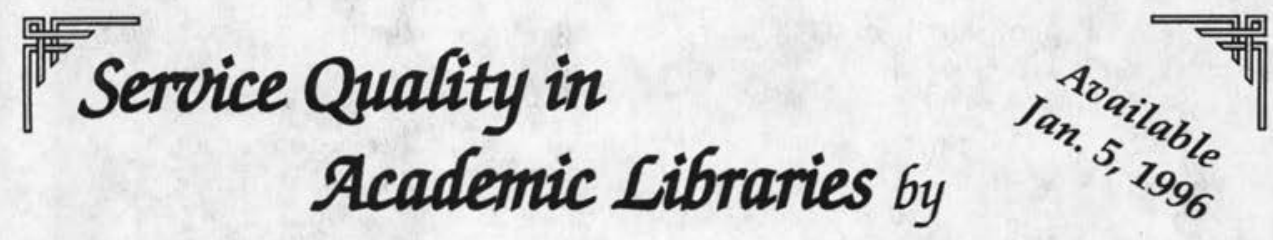

This book examines

service quality, identifies its essential elements and discusses ways in which service quality can be assessed quantitatively and qualitatively.

\section{Peter Hernom,}

\section{Simmons College, of Ellen Altman}

For information contact: Ablex Publisfing 355 Chestnut Street, Norwood, No 07648 